\title{
AUGUSTUS
}

\section{OS DESAFIOS DO GOVERNO BRASILEIRO PARA O ENFRENTAMENTO DA PANDEMIA DO CORONAVÍRUS}

\author{
Ricardo dos Santos de Jesus \\ Mestre em Desenvolvimento Local pelo Centro Universitário Augusto Motta (UNISUAM), Rio \\ de Janeiro, RJ. E-mail: ricardosj1984@gmail.com
}

Polyana Pazini Santos
Pós-Graduada em Coordenação Pedagógica pela Universidade Cândido Mendes (UCAM), Rio
de Janeiro, RJ. E-mail: polyana1980@gmail.com

Thiago Dias de Sousa Pós-Graduado em Direito Tributário pela Universidade Cândido Mendes (UCAM), Rio de Janeiro. E-mail: thiagodiasdesousa@gmail.com

\begin{abstract}
André de Oliveira Mestre em Ciências Ambientais pela Universidade Estadual da Zona Oeste (UEZO), Rio de Janeiro, RJ. E-mail: pbandreoliver@yahoo.com.br
\end{abstract}

Katia Eliane Santos Avelar Doutora, docente e Pesquisadora do Programa de Pós Graduação em Desenvolvimento Local do Centro Universitário Augusto Motta (UNISUAM), Rio de Janeiro, RJ. E-mail: katia.avelar@gmail.com

\section{RESUMO}

Em 2020, o mundo enfrenta uma Pandemia, caracterizada como Covid-19, que é uma doença respiratória altamente transmissível, o que levou mais de 180 países a uma das maiores crises sanitárias e econômicas de todos os tempos. $\mathrm{O}$ atual cenário exige respostas rápidas por parte dos governos, nos mais diferentes setores e contextos, sobretudo, nos países periféricos, onde há uma massa populacional carente de direitos fundamentais. Neste contexto, o presente estudo teve como objetivo a análise das ações de resposta do governo brasileiro frente aos desafios impostos pelo Covid-19. Trata-se de uma pesquisa bibliográfica e documental realizada durante os meses de março e abril de 2020. Destaca-se a importância da atuação do Estado brasileiro, por meio das políticas públicas de distribuição de renda e do seu aparato institucional, como suportes essenciais nesse momento de crise. Os resultados apontam que o Brasil realizou intervenções como medidas de preservação da vida e da economia por meio de ações de curto prazo que favoreceram tanto empresas, quanto as populações mais vulneráveis, utilizando-se do seu aparato institucional como o Sistema Único de Saúde (SUS), a Caixa Econômica Federal (CEF) e os Programas Sociais, tais como o Bolsa Família, dentre outros. Dessa forma, ficou evidenciado que o enxugamento do estado e/ou neoliberalismo realizado nas últimas décadas, principalmente, na esfera da saúde, pode trazer consequências drásticas para o caso de enfrentamento de crises como esta.

Palavras-chave: Pandemia. Neoliberalismo. Estado Brasileiro. Instituições Públicas. 


\title{
THE CHALLENGES OF THE BRAZILIAN GOVERNMENT FOR COPING OF THE CORONAVIRUS PANDEMIC
}

\begin{abstract}
In 2020, the world faces a Pandemic, characterized as Covid-19, which is a highly transmissible respiratory disease, which has led more than 180 countries to one of the greatest health and economic crises of all time. The current scenario demands rapid responses from governments, in the most different sectors and contexts, especially in peripheral countries, where there is a population mass lacking fundamental rights. In this context, the present study aimed to analyze the Brazilian government's response actions to the challenges imposed by Covid-19. This is a bibliographical and documentary research carried out during the months of March and April 2020. The importance of the performance of the Brazilian State, through public policies for income distribution and its institutional apparatus, is highlighted as essential supports in this moment of crisis. The results indicate that Brazil carried out interventions as measures to preserve life and the economy through short-term actions that favored both companies and the most vulnerable populations, using its institutional apparatus as the Unified Health System (SUS) ), Caixa Econômica Federal (CEF) and Social Programs, such as Bolsa Família, among others. Thus, it was evidenced that the wiping out of the state and / or neoliberalism carried out in the last decades, mainly in the health sphere, can bring drastic consequences in the case of facing crises like this.
\end{abstract}

Keywords: Pandemic. Neoliberalism. Brazilian State. Public Institutions. 


\section{INTRODUÇÃO}

A recente descoberta de um tipo de vírus altamente transmissível e preocupante, da família dos coronavírus, causador de uma doença respiratória denominada de Covid-19, que significa Coronavirus Disease (Doença do Coronavírus), ou ainda, síndrome respiratória aguda grave do coronavírus 2 (Sars-Cov-2), enquanto o "19" refere-se ao ano de 2019 em que foi relatado o surgimento da doença pela OMS (Organização Mundial da Saúde) (FUNDAÇÃO OSWALDO CRUZ, 2020). O surto se iniciou na China e, rapidamente, se alastrou entre centenas de países. Inicialmente, nem mesmo a maior entidade de saúde do assunto, a OMS, se manifestou e/ou informou de maneira contundente algo a respeito da disseminação dos casos. Após inexplicável resistência, em 11 de março de 2020, a OMS classificou a doença como uma Pandemia, ao se verificar o espalhamento do vírus para todos os continentes. (ORGANIZAÇÃO PAN-AMERICANA DE SAÚDE, 2020; LIU et al., 2020).

Diante de incertezas, diversos países (liberais e não liberais), mas, sobretudo, os mais liberais, negaram as evidências e não executaram com imediatidade as recomendações da OMS, principalmente, a de isolamento social. É o caso dos Estados Unidos (EUA), que atualmente, enfrenta uma das maiores crises econômico-social de sua história. (DOMINGUES; CARDOSO; MAGALHÃES, 2020).

Dessa forma, esse estudo teve como objetivo a análise das ações de resposta do governo brasileiro frente aos desafios impostos pela Covid-19. A metodologia utilizada se baseou em uma pesquisa bibliográfica e documental, realizada durante os meses de março e abril de 2020. Cabe destacar, que esse estudo é preliminar e foi realizado durante a Pandemia com uma limitada quantidade de dados científicos e estatísticos sobre a doença, bem como a alternância diária de informações, o que forçou a delimitação de datas e dados, mas que, ao final, não prejudicou o objetivo da pesquisa.

\section{O CONTEXTO NEOLIBERAL BRASILEIRO NO SÉCULO XXI}

As tensões entre o Estado intervencionista e o liberal desde muito tempo se fez presente no coração da política e se intensificou no Brasil entre os anos de 1980 e 1990, quando se iniciou as reforma do Estado; a partir da votação, em 1989, que culminou na eleição 
do presidente Fernando Collor de Mello. Desta forma, o Brasil avançou na implementação do projeto neoliberal. (CENCI; BEDIN; FISCHER, 2011).

Seguia-se a ideia da intervenção mínima, em que as "mãos invisíveis do mercado" seriam capazes de autorregular a economia, como proposto por Adam Smith, que é um dos principais representantes do liberalismo econômico, onde o Estado deve interferir o mínimo possível na economia e na vida dos cidadãos. Possuindo, assim, apenas três deveres, que são a defesa da sociedade contra os inimigos externos, a proteção dos indivíduos pela liberdade e a realização de obras públicas que não possam ser realizadas pela iniciativa privada. (SMITH, 2016).

Passado este momento introdutório, o Brasil continuou ascendendo presidentes com vertentes liberais, como Itamar Franco (1992-1995), Fernando Henrique Cardoso (1995-2002), Luiz Inácio Lula da Silva (Lula) (2003-2010), Dilma Rousseff (2010-2016), Michel Temer (20162018) e Jair Bolsonaro (2019-atual) que prosseguiram, de maneira crescente e abrangente, a dinâmica de consolidação da estratégia político-econômico neoliberal na sociedade brasileira, cujos processos descritos por Adam Smith foram acolhidos. (PORTO, 2009).

Durante este período houve uma definitiva redução nos orçamentos da maioria das pastas estratégicas, o que provocou profundas transformações nos serviços públicos, implicando na sua mercantilização (geralmente, capital estrangeiro), ou seja, o setor privado assume diversas administrações, um exemplo são as organizações sociais (OS) que fazem o papel do governo na saúde, com a premissa de aumentar a eficiência dos gastos existentes, criando concorrência, pagamento por resultado esperado e etecétera. (PORTO, 2009).

Neste contexto, afirma Pochmann (2017), que a condução de políticas públicas neoliberais não ocorreu durante o governo do Partido dos Trabalhadores (PT) (2003-2016), tendo em vista que o governo produziu uma política de expansão econômica e justiça social, aspirando interesses da massa trabalhadora brasileira e permitindo a redução da desigualdade social no Brasil.

No que diz respeito à consolidação do projeto neoliberal no Brasil, Pochmann (2017) e Boito Júnior (2006) concordam que tal demora se deve à extrema pobreza, grande desigualdade na distribuição de renda, infraestrutura deficitária, alta carga tributária, entre outros. Exatamente, por isso, que os governos atuantes de 1998 a 2016 priorizaram, entre 
outros aspectos, a redução da pobreza (incluindo os mais pobres em programas sociais) e a melhoria na distribuição de renda, com destaque, neste trabalho, para o ex-presidente Lula.

Para Giambiagi e Horta (2019) após o impeachment da presidenta Dilma Rousseff, seus sucessores aprofundaram, ainda mais, as reformas para enxugamento da máquina pública, a iniciar pela aprovação da Proposta de Emenda à Constituição (PEC) do Teto dos Gastos Públicos, que resultou, por 20 anos, na limitação do crescimento das despesas dos três poderes, alteração de diversos artigos da Consolidação das Leis Trabalhistas (CLT), que ficou conhecida como a Reforma Trabalhista, na qual flexibilizou as jornadas de trabalho, acordos coletivos e processos judiciais, além da Reforma Previdenciária que alterou as regras nas aposentadorias.

Sales e Cardoso (2020) destacam que o modelo neoliberal, quando mal introduzido pode trazer consequências drásticas para um país, pois a importação e exportação de produtos comercializados tende ao não favorecimento de economias periféricas, como o Brasil. Neste sentido, o país inclina-se a afrouxar as legislações trabalhistas e previdenciárias, favorecendo a maior exploração do trabalhador e, por conseguinte, tornando o país refém na exportação de matérias-primas para os países industrializados que geram a tão festejada riqueza agregada, através de patentes internacionais registradas e parques industriais mais tecnologicamente produtivos. Além disso, estes países desenvolvidos fazem acordos de parceria comercial onde os custos de mão de obra são mais baratos e, não raros, semiescrava.

\section{O LIBERALISMO À MODA BRASILEIRA}

Como explicitado acima, as tendências liberais apontam no sentido de que o mercado poderia regular a si mesmo, sem a necessidade de intervenção do Estado e de mecanismos de controle da economia. Historicamente, essas experiências em países periféricos, como o Brasil, demonstram a necessidade de intervenções, por parte, do Estado para auxiliar a sociedade frente as suas crises (sociais ou econômicas).

O Brasil precisa reduzir as despesas públicas, abrir concessão de algumas estatais, porém, segundo o observatório das estatais, produzido pela Fundação Getúlio Vargas (FGV), é estratégico manter setores e programas que suportam o país nos momentos de crise, seja promovendo o desenvolvimento ou induzindo a inovação, como é o caso do Sistema Único de 
Saúde (SUS) - na saúde, da Caixa Econômica Federal (CEF) e o do Banco Nacional do Desenvolvimento Econômico e Social (BNDES) - nas finanças e do Programa Bolsa Família - na distribuição de renda, entre outras. (HOLLAND, 2017; BOITO JÚNIOR, 2006).

Anuatti-Neto et al. (2017) refuta essa ideia ao afirmar que é possível que o Estado cresça economicamente sem dono de empresas estatais, bastando para isso, um bom marco regulatório e boas agências de fiscalização, e, desta forma, promover um bom desempenho, governança e a competição. $O$ autor explica que "o liberalismo brasileiro veio pra ficar, mas é preciso que o Estado faça querer dar certo, deixando o debate político de lado e sendo pragmático no combate à corrupção, à desburocratização e no desempenho eficiente da gestão." (ANUATTI-NETO et al., 2017, p. 2).

\section{O CAMINHO DA PANDEMIA}

Em dezembro de 2019, foi identificado na cidade de Wuhan, na China, o primeiro caso da doença respiratória grave denominada de Covid-19, que significa Coronavirus Disease (Doença do Coronavírus), ou ainda, síndrome respiratória aguda grave do coronavírus 2 (SarsCov-2), enquanto o "19" refere-se ao ano em que foi relatado o surgimento da doença pela OMS (Organização Mundial da Saúde). (FUNDAÇÃO OSWALDO CRUZ, 2020). O coronavírus se espalhou rapidamente pelo mundo (LIU et al., 2020). Segundo a Organização Mundial da Saúde (OMS) esta doença representa uma ameaça à saúde pública global $\left(\right.$ ESPII) ${ }^{1}$ e às economias locais. Até 15 de abril de 2020, o número de países atingidos era de pelo menos 180 e mais de dois milhões de infectados, sendo contabilizada mais de 140 mil mortes pelo mundo. (WORLD HEALTH ORGANIZATION, 2020; QUE, 2020).

Um número tão grande de pessoas infectadas e mortas exige uma urgência no assunto; a disponibilização de medicamentos, ampliação dos leitos de urgência e equipamentos de proteção individual (EPI) para os profissionais da saúde e população devem estar acessíveis para combater e controlar a pandemia.

Diante desse quadro, foi com muita resistência que, no dia 11 março de 2020, a OMS classificou a doença como uma Pandemia, significando que a doença espalhou-se por todos

\footnotetext{
${ }^{1}$ Representa o mais alto nível de alerta da OMS, conforme previsto no Regulamento Sanitário Internacional. (WORLD HEALTH ORGANIZATION, 2020).
} 
os continentes, com transmissão sustentada de pessoa para pessoa, dificultando a sua identificação (WORLD HEALTH ORGANIZATION, 2020). Em pronunciamento oficial o porta-voz da instituição, o Diretor-Geral Tedros Adhanom Ghebreyesus, declarou:

A preocupação em reclassificar a doença como Pandemia era o receio de a palavra ser usada de maneira leviana ou descuidada. É uma palavra que, se mal utilizada, pode causar medo irracional ou aceitação injustificada de que a luta acabou, levando a sofrimento e mortes desnecessários² (ORGANIZAÇÃO PAN-AMERICANA DE SAÚDE, 2020).

Os primeiros casos da doença de coronavírus no Brasil foram confirmados em fevereiro de 2020, através de pessoas que vieram de outros países (já contaminados), como China, Itália, Espanha e Estados Unidos. Desde então, os governos federais e estaduais introduziram uma série de medidas recomendadas pela própria OMS para garantir a prevenção e a preservação da capacidade dos serviços de saúde.

No primeiro momento, tratava-se apenas de manter um distanciamento social da população, na medida do possível. Entretanto, com o avanço da doença os estados regulamentaram medidas de saúde pública, determinando a obrigatoriedade do isolamento social - significando que a população devesse permanecer em quarentena, restrita de seus direitos fundamentais - culminando no fechamento de escolas, praças, praias, restrições no comércio, nos transporte e nas empresas que não se enquadraram nos serviços essenciais (saúde, alimentação, segurança, limpeza urbana, entre outros). (VENTURA; AITH; RACHED, 2020).

Para a OMS e Ventura et al. (2020), as medidas de isolamento foram consideradas importantes, devido à letalidade da doença, sobretudo nos idosos e pessoas com comorbidades $^{3}$. Estima-se que cerca de $1 \%$ da população brasileira poderia encontrar-se infectada no pico da doença, ou seja, mais de dois milhões de pessoas, caso o isolamento obrigatório não fosse e não continue sendo aplicado.

Os governos trabalham pautados na llustração 1, chamada de "a curva de contaminação do novo coronavírus", na qual simula a quantidade de infectados a partir do

\footnotetext{
2 A tradução do pronunciamento foi feita pela Representação da Organização Pan-Americana da Saúde/Organização Mundial da Saúde (OPAS) a título informativo, não se trata de tradução oficial.

3 Patologias pré-existentes, sob predisposições para desenvolvimentos de doenças complementares ou mesmo suplementares.
} 
primeiro caso diagnosticado, tanto com as medidas preventivas, quanto sem as medidas - na qual a transmissão está fora de controle.

Figura 1- Simulação da curva de contaminação pelo novo coronavírus.

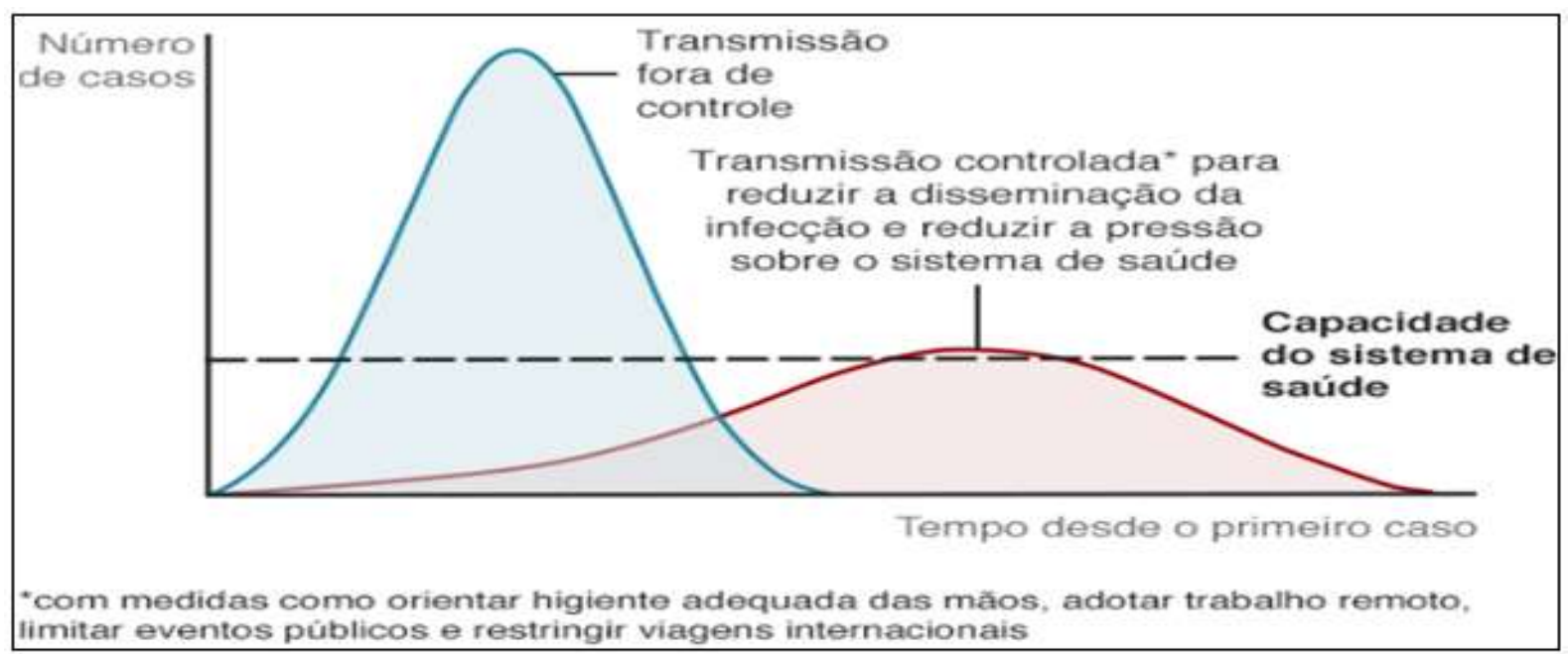

Fonte: GUROVITZ (2020) ${ }^{4}$.

Um estudo revelou que, na cidade de São Paulo, o pico da doença sem as medidas preventivas faria o sistema de saúde entrar em colapso já no mês de abril de 2020. Os dados revelaram, também, que todos os estados brasileiros, incluindo o Distrito Federal, apresentarão esgotamento da saúde pública e privada no pico da doença (UNIVERSIDADE DE SÃO PAULO, 2020). Para Domingues, Cardoso e Magalhães (2020) existem duas formas de impedir que a simulação do pior cenário previsto pelo o modelo no pico da curva de transmissão fora de controle se torne realidade:

\footnotetext{
A primeira é aumentar a infraestrutura do sistema de saúde, com a disponibilização de mais leitos, pessoal e insumos, adequando-os à demanda. Isso, porém, é inviável em curto prazo: o máximo que se consegue fazer é abrandar o impacto e adiar o colapso em alguns dias. A segunda forma, mais eficiente e viável, é o isolamento social, pois com ele a taxa diária de transmissão é reduzida e a curva de contaminados achatada. Assim, o número simultâneo de pacientes que demandam leitos de internação cai muito, e o sistema consegue atender mais pessoas ao longo do tempo. (DOMINGUES; CARDOSO; MAGALHÃES, 2020).
}

O isolamento social foi desde o início um dos "remédios" no combate a doença, com efeito, foi promulgada a Lei n. 13.979, de 06 de março de 2020, referida como a "Lei de Quarentena", que oficializou a parada obrigatória dos serviços não essenciais em praticamente todo o Brasil (decisões estaduais). (BRASIL, 2020a).

\footnotetext{
${ }^{4}$ Adaptado de Harris. (ROBERTS, 2020).
} 
A situação apresentada impactou diretamente na economia global, e segundo projeções do Fundo Monetário Internacional (FMI), o Brasil poderá ter um recuo de 5,3\% no Produto Interno Bruto (PIB), retroagindo, assim, em 10 anos. (ORGANIZAÇÃO DAS NAÇÕES UNIDAS, 2020).

Notícias que têm deixado o atual Presidente da República desorientado, uma vez que toda sua estratégia de governo segue num emaranhado, entre ter que atuar fortemente com o Estado para ajudar a salvar vidas e manter ativa a economia, sem abrir mão da sua agenda de reformas liberais, como as tributária (com foco na redução de impostos) e administrativa do Estado.

\section{A INTERVENÇÃO DO ESTADO BRASILEIRO NO CASO DA PANDEMIA}

Desde o início do seu mandato, o Presidente Jair Bolsonaro, bem como o Ministro da Economia Paulo Guedes, já expusera inúmeras vezes serem contra qualquer intervenção do Estado, inclusive, afirmando, por vezes, que apenas os regimes comunistas objetivam o controle absoluto estatal. Neste sentido, circula nas redes sociais de apoiadores do presidente que até a Covid-19 é comunista, fazendo uma referência à China, local do surgimento do primeiro caso da doença. (HERDY, 2020).

O cenário atual da doença evidencia a situação calamitosa que o Brasil enfrenta no seu sistema de saúde, por isso os entes legislativo e judiciário entraram no rol para discutir e validar estratégias essenciais no combate a Pandemia. Os programas de suporte à sociedade brasileira, incluído a ajuda aos estados, pode chegar a R\$ 1 trilhão de reais. (BRASIL, 2020b), saldo esse que estão totalmente desalinhados com as estratégias iniciais do Presidente.

Como o governo federal propõe um sistema liberal e a doença pode atrapalhar este projeto, essa administração adotou, desde o início da Pandemia, atitudes de minimização da doença. Em pronunciamento oficial, veiculado no dia 24 de março, o presidente afirmou: “[...] pelo meu histórico de atleta, caso fosse contaminado pelo vírus, não precisaria me preocupar, nada sentiria ou seria acometido, quando muito, de uma gripezinha ou resfriadinho [...]" (BRASIL, 2020c). Em outro trecho declarou "a dose do remédio não pode ser maior que a doença." (BRASIL, 2020c). 
Esse tipo de postura, também, foi adotado por outros chefes de estado liberais, como o presidente americano Donald Trump, que fez declarações diárias durante o surto e sempre minimizando o impacto da doença na saúde e na economia, até o seu país atingir dez mil mortes, forçando-o a amenizar seu discurso inicial. Assim, ações similares adotadas pelo Brasil foram tomadas. Em abril de 2020, três meses após a confirmação do primeiro caso, os EUA contabilizam uma média de mais de mil mortos por dia. (BARRÍA, 2020).

O país se divide em argumentações divergentes, em que de um lado figura a maioria do Executivo - querendo a retomada da rotina na economia com a volta da abertura de empresas e dos comércios e do outro lado o Legislativo, a maioria dos governadores e o próprio Ministério da Saúde - os quais defendem as orientações da OMS pela continuidade da quarentena, até que os sistemas públicos federal, estadual e municipal (e mesmo privados) encontrem-se estruturados com elevado número de leitos, respiradores e pessoal treinado, de forma a atender um enorme contingente de infectados (denominado de achatamento da curva). (CRODA; GARCIA, 2020; DOMINGUES; CARDOSO; MAGALHÃES, 2020).

Em suma, a quarentena não objetiva tecnicamente reduzir o número de infectados, mas postergar os contágios até que os sistemas de saúde tenham condições de atendimento médico com um mínimo de decência humana. Diferentemente de outras pandemias, ocorridas em outros momentos da história, como a Peste Negra e a Gripe Espanhola (com estimativas de até 300 milhões de mortos nos séculos XIV e XX, respectivamente) (WILLIAMS, 2020), esta quarentena tem um segundo objetivo: ganhar tempo para que as pesquisas científicas (ocorrendo em todo o mundo) com antirretrovirais cheguem à máxima conclusão de eficácia medicamentosa. (BRASIL, 2020d; LIU et al., 2020).

Em meio à crise, grandes esperanças surgem com os medicamentos Remdesivir, Cloroquina, Azitromicina, Ritonavir, entre outros. Cientistas brasileiros, abalizados em entrevista coletiva pelo Min. da Tecnologia, Marcos Pontes, afirmam haver descoberto uma combinação de retrovirais com tendência a se obter $94 \%$ de eficácia para o tratamento da Covid-19, mas o resultado só estará disponível em maio de 2020 (após a entrega deste estudo). (KAFRUNI, 2020).

Dados não oficiais, de universidades federais, estimam que o Brasil já possua mais de 1,6 milhão pessoas infectadas de Covid-19, mesmo sob a quarentena. O governo, por sua vez, aprovou uma serie de medidas intervencionistas do Estado, através de políticas públicas já 
existentes no plano governamental, para minimizar os impactos na vida da população, sobretudo, na saúde e na economia. (NÚMERO, 2020).

\subsection{O Sistema Único de Saúde (SUS) brasileiro}

O SUS é um sólido sistema de saúde e único no mundo com capacidade para atender uma população acima de 200 milhões de pessoas (VIACAVA et al., 2018). Essa situação coloca - Brasil à frente entre os grandes países que praticam a saúde pública social-democrática, como Canadá, Reino Unido, Itália e Suécia, atendendo, por ano, cerca de 180 milhões de pessoas e realizando cerca de 2,8 bilhões de atendimentos, desde procedimentos ambulatoriais simples aos atendimentos de alta complexidade, como transplantes de órgãos, dentre outros. (FUNDAÇÃO OSWALDO CRUZ, 2020; VIACAVA et al., 2018).

Um sistema como o SUS, administrado pelo Estado, sem discriminação e democrático, ao alcance e podendo ser utilizado por qualquer cidadão, é essencial diante de uma crise como essa do Covid-19, vírus que é transmitido através das mucosas do corpo, como: boca, nariz e olhos, provocando infecções respiratórias, que afeta a todos, sem distinção, democraticamente, porém, que está mostrando as contradições e divergências de opiniões (políticas, econômicas e sociais) diante do pedido da OMS para o distanciamento social. (WORLD HEALTH ORGANIZATION, 2020; DOMINGUES; CARDOSO; MAGALHÃES, 2020).

Magnoli (2020) e Martins (2020) contribuem ao dizerem que as doenças em geral não são democráticas, pois suas incidências são determinadas pela renda, moradia, idade, gênero e raça. No caso do coronavírus, não é diferente, as populações vulneráveis já estão no grupo de risco, não só pela letalidade social em que vivem, mas por comorbidade comum que atingem estas populações como hipertensão e diabetes.

Trata-se de um grupo que carrega dificuldades no seu viver, provocada por um racismo estrutural e estruturante, que começa desde a informação que chega a essa população até o acesso a exames para detecção do vírus, principalmente no que se chama de casos suspeitos. (MARTINS, 2020).

$\mathrm{Na}$ visão de Magnoli (2020) isso explica o posicionamento contrário dessas populações sobre os governos que desmantelam o sistema de saúde, em prol do favorecimento do sistema privado. Para ele, o vírus desembarcou no Brasil através das classes média e alta - trazidas do exterior, mas se espalhou rapidamente e, segundo o Ministério da 
Saúde, alcançará os mais pobres que vivem nas favelas, gerando uma avalanche nos hospitais públicos. (BRASIL, 2020d).

Os primeiros casos de coronavírus em populações vulneráveis no Rio de Janeiro foram de empregadas domésticas que contraíram de seus empregadores que voltaram de países europeus. (GOVERNO, 2020).

Essas populações fazem parte dos serviços essenciais (são em sua maioria os profissionais de saúde, do supermercado, da farmácia, da limpeza urbana e da segurança) que continuam se locomovendo de transporte público lotado para poder ir trabalhar. A pergunta que fica é: como fazer a quarentena nessas condições? Vão se isolar aonde? Num barraco de dois metros quadrados, com filhos, avós, esposa? Como vão se cuidar? É urgente que as autoridades sanitárias e políticas desenvolvam estratégias de contenção da Covid-19 nesses grupos, ou vai se presenciar uma carnificina sem precedentes. (MARTINS, 2020).

O relatório da Agência Nacional de Saúde Suplementar (ANS) revela que apenas $30 \%$ dos brasileiros possuem planos de saúde, sendo em sua maioria as classes mais altas (AGÊNCIA NACIONAL DE SAÚDE SUPLEMENTAR, 2019). Segundo o SUS, a rede privada detém $56 \%$ dos leitos de Unidade de Tratamento Intensivo (UTI). Isto mostra o colapso e a mortandade que será caso esta doença adentre nas comunidades mais carentes. (BRASIL, 2020e).

A crise sanitária causada uma pela covid-19 expôs a ferida aberta da desigualdade entre o sistema público de saúde e o suplementar. Apesar de o número de leitos totais de UTI no Brasil (público e privado) estarem de acordo com a recomendação da OMS, de 1 a 3 para cada 10 mil habitantes, estima-se que mais da metade deles estão direcionados a um quarto da população que possui plano de saúde. (MAGNOLI, 2020, p. 1).

Um dado ainda mais preocupante é que, em 2018, apenas $10 \%$ dos municípios brasileiros tinham leitos de UTI (CONSELHO FEDERAL DE MEDICINA, 2018), o que mostra a má distribuição pelas regiões brasileiras, portanto, caso a doença avance para regiões menores, é possível que não haja assistência para todos, uma vez que esta situação não deve ter se alterado significativamente nos últimos dois anos.

Essa situação que corrobora ainda mais para necessidade de fortalecimento do SUS, através do melhoramento da gestão, ampliação da rede e mitigação da falta de recursos. Aí reside há preocupação dos estados e municípios em seguirem as orientações da OMS.

Mesmo diante dos entraves, as federações juntaram esforços e esperam até o final de abril de 2020 terem criado vinte mil novos leitos para atender os casos mais graves de Covid-19, além da compra de materiais e equipamentos que já fomentou mais de $R \$ 10$ 
bilhões só na saúde. Como já dito, somando todas as áreas este saldo pode chegar a $\mathrm{R} \$ 1$ trilhão. (BRASIL, 2020b).

Além desses esforços, o Superior Tribunal Federal (STF) recebeu estudos e propostas apontando que o Estado brasileiro deve criar uma fila única para acesso as UTIs, seja ela pública ou privada, caso o número de infectados caminhe para o pico - previsão é no fim de abril de 2020. (SUPREMO TRIBUNAL FEDERAL, 2020).

Essa medida busca evitar e reparar lesão a preceitos fundamentais correspondentes ao direito à saúde, à vida, à igualdade, bem como ao valor fundamental da dignidade da pessoa humana e, ainda, ao propósito dos constituintes de construir uma sociedade justa e igualitária, abrigados nos arts. $1^{\circ}$, III; $3^{\circ} ; 5^{\circ}$, caput; $6^{\circ} ; 23, \mathrm{II} ; 24, \mathrm{XII}$; 194; 196; 197; 198; 199; 200; 227 e 230, todos da Constituição Federal. (BRASIL, 2020f).

Magnoli (2020) defende que o governo federal estabeleça um acordo com as operadoras de planos de saúde no cenário de sobrecarga das UTIs da rede pública, argumentando que tal situação já está prevista na CF, no seu artigo 5ํ, inciso XXV que prevê: "em caso de perigo público iminente, a propriedade particular pode ser usada por autoridade competente, mediante indenização posterior ao proprietário em caso de dano" (BRASIL, 1988). O Estado do Rio de Janeiro se antecipou ao governo federal e tramitou o projeto de Lei Estadual n. 2324/2020, que garante organizar e coordenar os leitos de UTIs, públicas e privadas, civis e militares do estado para tratar os casos de coronavírus. (ASSEMBLEIA LEGISLATIVA DO ESTADO DO RIO DE JANEIRO, 2020).

Para Vecina Neto (2016), mesmo com problemas, sem o SUS, o Brasil seria uma indigência social, na qual a grande massa populacional pobre não teria acesso às campanhas de vacinação e as crianças não teriam pediatras, ficariam dependentes de ajuda alheia, assim como acontecia antes da criação do sistema.

[...] era apenas um grupo de visionários ligados à esquerda do espectro político que defendeu a ideia de que seria possível criar um sistema que oferecesse saúde gratuita a todos os brasileiros. Parecia divagação de sonhadores. (VECINA NETO, 2016, p. 10).

Diante de todo este contexto fica evidente que o SUS é disparado o maior e o mais importante programa de investimento de impostos do país e um setor estratégico para o governo, já que atende $75 \%$ da população. Perto dele, outros programas, como o bolsa família, tornam-se pequenos ao saber que sua aplicação é de apenas $10 \%$ do que é investido anualmente no SUS. (TEIXEIRA, 2019). 


\subsection{O Programa de Transferência de Renda - Bolsa Família}

O programa social denominado "Bolsa Família" é um programa federal de transferência direta de renda, através de um banco público, a Caixa Econômica Federal (CEF), destinado às famílias em situação de pobreza (renda per capita de até R\$ 178 por mês) (CAIXA ECONÔMICA FEDERAL, 2020a). Este programa possui cadastrado cerca de 15 milhões de famílias, ou seja, um terço da população brasileira.

As famílias que se enquadram nos pré-requisitos exigidos para concessão do benefício, no momento recebem, por mês, um valor que varia de $R \$ 41$ a $R \$ 372$, a depender da sua situação econômica. (CAIXA ECONÔMICA FEDERAL, 2020a).

\footnotetext{
A característica central do programa é que ele procura associar a transferência do benefício financeiro ao acesso a direitos sociais básicos, como saúde, alimentação, educação e assistência social. O Bolsa Família tem dois objetivos básicos: combater a miséria e a exclusão social, e promover a emancipação das famílias mais pobres. (WESSHEIMER, 2006, p. 12).
}

Este cenário, de isolamento social, fechamento dos mercados interno e externo, piorou ainda mais a vida das pessoas mais pobres que regularmente trabalham por conta própria, sem nenhuma formalização de atividade, garantia trabalhista ou de renda mínima. (BRASIL, 2020g).

O governo estima que 20 milhões de brasileiros, ainda, não estão incluídos no programa, desta forma, está flexibilizando o cadastramento dessas populações, pretendo, assim, prestar assistência a cerca de 38 milhões de brasileiros (BRASIL, 2020g). Outra ação importante são que, essas famílias, em decorrência da Pandemia, não irão receber os valores normais devidamente pagos pelo bolsa família e, sim, um auxílio emergencial que será detalhado mais a frente.

Para a Câmara dos Deputados (2020) os recursos destinados ao bolsa família, serão vitais para arcar com os custos de alimentação das populações mais vulneráveis, que aumentaram durante a pandemia, uma vez que as crianças não estão fazendo suas refeições na escola. 


\subsection{O papel da Caixa Econômica Federal (CEF)}

A CEF é uma instituição financeira, sob forma de empresa pública, vinculada ao Ministério da Economia. Incluída no Sistema Financeiro Nacional (SFN), ela é fundamental na política de crédito do governo federal e tem como missão o desenvolvimento do país através da promoção da cidadania; deste modo, o banco tem seu apelo, sobretudo nas camadas sociais mais populares. (CAIXA ECONÔMICA FEDERAL, 2020b).

Este posicionamento estratégico facilitou a operacionalização do Plano Emergencial de Emprego e Renda (PEER), que garantiu por três meses um auxílio de $\mathrm{R} \$ 600$ reais para os mais vulneráveis, durante a pandemia, definido como: os integrantes do bolsa família, autônomos, informais, micro empreendedor individual (MEI), desempregados e similares, podendo chegar até o valor de $\mathrm{R} \$ 1.200$ para outras famílias, como mães que são consideradas chefes de família. (BRASIL, 2020g).

O Ministro Paulo Guedes, em uma entrevista, elogiou a luta diária e a força das instituições brasileiras neste momento crítico e disse que o fato do Brasil ter instituições como a CEF e o Programa Bolsa Família, facilitam muito as operações do governo de distribuição destes recursos financeiros aos mais necessitados. (PAULO, 2020).

A CEF prorrogou, também, por três meses, o pagamento de alguns dos empréstimos adimplentes em sua base, sendo o mais expoente o financiamento de imóveis. Na mesma direção seguiram outros bancos privados. (BRASIL, 2020g).

\subsection{Outras Intervenções Anunciadas}

Passados duas mil mortes no Brasil e com as autoridades da saúde informando que este número poderia ser maior, uma vez que não se tem a quantidade de exames necessários de covid-19 para saber a real proporção, o presidente anunciou, através de diversas Medidas Provisórias (MPs), durante o mês de março de 2020, outras medidas para salvar a economia brasileira, tanto no âmbito social, que beneficiará diretamente os cidadãos, quanto no âmbito empresarial, que beneficiará as empresas, sobretudo as pequenas e médias que estavam começando a demitir seus funcionários e ameaçava decretar falência por conta da recessão econômica provocada pela quarentena. 
A Figura 2 apresenta um paralelo das principais ações desenvolvidas pelo governo brasileiro na tentativa de salvar a economia.

Figura 2- Paralelo das Medidas Provisórias anunciadas pelo Governo Brasileiro.

\begin{tabular}{|c|c|}
\hline APOIO ÀS EMPRESAS & APOIO AOS CIDADÃOS \\
\hline $\begin{array}{l}\text { Desoneração temporária do pagamento de } \\
\text { taxas, encargos e contribuições da folha } \\
\text { salarial, como o Fundo de Garantia por } \\
\text { Tempo de Serviço (FGTS). }\end{array}$ & $\begin{array}{l}\text { Plano de Auxílio Emergencial, por três } \\
\text { meses, no valor de } \mathrm{R} \$ 600 \text { até } \mathrm{R} \$ 1.200 \text { para } \\
\text { mães consideradas chefes de família. }\end{array}$ \\
\hline 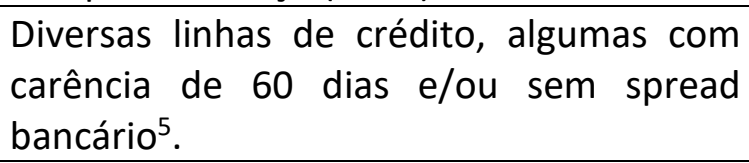 & Antecipação \\
\hline $\begin{array}{l}\text { Liberação de } \mathrm{R} \$ 40 \text { bilhões em linhas de } \\
\text { crédito específicas para pagamento de } \\
\text { funcionários, na qual o crédito entrará } \\
\text { direto na conta do trabalhador e a empresa } \\
\text { se compromete a não demiti-lo durante a } \\
\text { Pandemia. }\end{array}$ & $\begin{array}{l}\text { Pausa no Pagamento de até três parcelas de } \\
\text { financiamento de imóvel e empréstimos } \\
\text { pela Caixa Econômica Federal (CEF). }\end{array}$ \\
\hline $\begin{array}{l}\text { R\$ } 5 \text { bilhões para o programa de } \\
\text { agronegócio (Proger) e agricultura familiar } \\
\text { (Pronaf). }\end{array}$ & $\begin{array}{l}\text { Suspensão de cobrança da dívida ativa e } \\
\text { novas condições de parcelamento. }\end{array}$ \\
\hline $\begin{array}{l}\text { R\$ } 5 \text { bilhões para o programa de amparo ao } \\
\text { trabalhador (FAT). É desta conta que sairá } \\
\text { a ajuda aos taxistas (autônomos). }\end{array}$ & $\begin{array}{l}\text { Inclusão de mais de um milhão de pessoas } \\
\text { no programa bolsa-família. }\end{array}$ \\
\hline $\begin{array}{l}\text { Mais aportes do BNDES para as Fintechs } \\
\text { (modelos de negócios inovadores). }\end{array}$ & $\begin{array}{l}\text { Prorrogação da entrega do Imposto de } \\
\text { Renda (IR) para junho de } 2020 \text {. }\end{array}$ \\
\hline $\begin{array}{l}\text { Revisão dos acordos coletivos para } \\
\text { estabelecer redução da jornada de trabalho }\end{array}$ & $\begin{array}{l}\text { Isenção por três meses do pagamento da } \\
\text { conta de luz, as famílias de baixa renda. }\end{array}$ \\
\hline $\begin{array}{l}\text { Programa emergencial para a manutenção } \\
\text { do emprego (PEME) na qual o governo } \\
\text { complementará o salário do funcionário } \\
\text { que tiver redução dos ganhos, por conta da } \\
\text { MP que permitiu as empresas reduzirem a } \\
\text { jornada de trabalho, desta forma reduzindo } \\
\text { igualmente os salários. }\end{array}$ & $\begin{array}{l}\text { Liberação do saque do FGTS, até um salário- } \\
\text { mínimo, em junho de } 2020 \text {. }\end{array}$ \\
\hline $\begin{array}{l}\text { Suspensão temporária dos contratos de } \\
\text { trabalho por até } 4 \text { meses. Assim o Estado } \\
\text { custeará o trabalhador através do seguro- } \\
\text { desemprego neste período. }\end{array}$ & $\begin{array}{l}\text { Redução compulsória nas taxas de juros de } \\
\text { cheque especial e cartões de crédito. }\end{array}$ \\
\hline
\end{tabular}

\footnotetext{
${ }^{5}$ Spread Bancário são os lucros dos bancos, calculado pela diferença entre o que banco paga a um investidor (rendimentos) e o que ele cobra ao conceder um empréstimo (juros). (BANCO CENTRAL DO BRASIL, 2016).
} 


\begin{tabular}{|c|c|}
\hline $\begin{array}{l}\text { Retirada do Imposto sobre Produtos } \\
\text { Industrializados (IPI) e das tarifas de } \\
\text { importação para produtos médicos- } \\
\text { hospitalares. }\end{array}$ & Antecipação do 13ㅇ dos Aposentados. \\
\hline- & $\begin{array}{l}\text { Impedimento de corte de fornecimento de } \\
\text { água, luz e gás no caso de inadimplência } \\
\text { durante a Pandemia. }\end{array}$ \\
\hline
\end{tabular}

Fonte: Autor (2020), adaptado de acordo com Brasil (2020b).

Flaeschen (2020) entende que embora o governo tenha anunciado estas medidas econômicas que amenizará os efeitos da Pandemia sobre a economia e a renda dos trabalhadores, demorou a serem tomadas. Esse também é o entendimento do presidente da câmara dos deputados que em declaração exclamou:

O governo demorou, não fez, de forma sistêmica, primeiro pacote organizado [...] Precisa sempre do passo de alguém para estimular o governo a dar outro passo [...] O Brasil está muito tímido nas tomadas de decisões e fica sempre a reboque das decisões de outros países ou de pressões setoriais. (CORONAVÍRUS, 2020).

Flaeschen (2020) alerta que o tempo de ação das medidas é tão importante quanto às próprias ações, pois as famílias em situação de pobreza já está há mais de um mês de quarentena, desprotegidas de renda e sem as condições mínimas de sobrevivência.

A excessiva burocracia estatal pode estar gerando essa lentidão no governo que tem receio de serem punidos posteriormente por infligirem alguma regra. Esta situação é explicada pelo Presidente da República em entrevista: “[...] a burocracia é enorme, jurídica e política, e qualquer erro por parte do governo pode resultar num crime de responsabilidade." (GUIMARÃES, 2020).

A sociedade não quer entender os ditames burocráticos da política, como já está ávida por serviços públicos e cansada de promessas de campanha ela clama pelas ações que "matem" a sua fome. (SILVA, 2018).

\section{CONSIDERAÇÕES FINAIS}

Tendo como referência as pesquisas e as análises realizadas no desenvolvimento desse texto, conclui-se que a atual e massacrante crise vivenciada por praticamente todos os governos globais é melhor combatida em países periféricos quando os arranjos institucionais 
do Estado estão disponíveis aos governos, fazendo-os operacionalizar as ações contra agentes agressores e seus efeitos, de forma a minimizar sofrimentos humanos, atendendo e beneficiando mais facilmente a sua massa populacional.

Uma das razões que corrobora com a intervenção do Estado na saúde e no combate e esta crise é de que, como $80 \%$ da população brasileira é atendida pelo SUS, isso significa que mesmo o Brasil executando as políticas públicas, citadas neste estudo, como ferramentas ao combate ao Covid-19, realizando todos os pagamentos e/ou distribuição da renda devidas as famílias que fazem jus aos benefícios, em caso de contaminação, seria uma realidade impossível que essas famílias de baixa renda custeiem o tratamento em desfavor do vírus em hospitais particulares, em virtude dos altos custos e despesas comparados aos valores concedidos dos benefícios.

Como foi entendida, a ideia central deste texto foi mostrar que o Brasil há décadas vem numa crescente liberal que provoca profundas transformações política, econômica e social, muitas importantes, como a desburocratização e as reformas do estado, entretanto, deve haver cautela sobre as privatizações de setores estratégicos e importantes para o Brasil, reconhecendo as fragilidades nacionais, situação latente durante esta crise. (PORTO, 2009).

Por outro lado, países com economias mais liberais, como a dos EUA, que está padecendo durante a crise do Covid-19 em virtude da doença ter se espalhado mais rapidamente. Como o país não conta com um sistema público de saúde e uma legislação trabalhista que proteja seus trabalhadores, o que permite que sejam remunerados somente por horas trabalhadas, sem licença medica ou férias remuneradas, muitos desses trabalhadores, quando doentes, sem cobertura médica, não procuram os hospitais por medo dos altos custos com despesas medicas. (SZALAY, 2020).

Assim, supostamente, muitos foram trabalhar mesmo doentes, o que facilitou a disseminação da Covid-19 no país. O EUA tem 250\% mais infectados que a Espanha, segundo colocado no ranking de contaminação, e já amarga à marca de 42.550 mil mortos de Covid-19 (20 de abril de 2020).

Este estudo foi realizado antes do chamado "pico da doença" no Brasil e nos EUA, portanto, todos os números apresentados tendem a aumentar, comprovando a necessidade imprescindível da intervenção não só do Estado, mas de todos os atores (setores público e 
privado e sociedade civil) na busca de soluções para a restituição da normalidade, com o mínimo de mortandade.

Mesmo o Brasil caminhando no processo neoliberal é interessante à condução do processo econômico pelo Estado, uma vez que há preservação do mercado a intempéries. É possível dizer, assim, que o capitalismo não demanda efetivamente a minimização do Estado, mas sim, que a atuação pública esteja a serviço do bem estar social e de seus interesses.

Portanto, verificou-se que houve uma intervenção do estado no combate ao novo coronavírus, sobretudo, por meio do programa de distribuição de renda e isolamento social. Entretanto, há a necessidade da melhoria do acesso à saúde, bem como políticas públicas voltadas às populações mais vulneráveis, que são na sua maioria de baixa renda, uma vez que o combate a essa pandemia pode ser considerado um dos maiores desafios enfrentados pelo governo e a sociedade na atualidade. Para tanto, o estudo destaca a importância da atuação dos arranjos institucionais do Estado brasileiro, que incluem as instituições públicas e seus programas de distribuição de renda, como suportes essenciais para o enfrentamento da Covid-19, a despeito do paradoxo vivido pelo governo, que fomenta uma política neoliberal, com menos participação da máquina pública nos processos econômicos e sociais.

\section{REFERÊNCIAS}

AGÊNCIA NACIONAL DE SAÚDE SUPLEMENTAR. Dados gerais: beneficiários de planos privados de saúde, por cobertura assistencial (Brasil - 2010-2020). [Rio de Janeiro]: ANS, 2020. Disponível em: https://www.ans.gov.br/perfil-do-setor/dados-gerais. Acesso em: 14 abr. 2020.

ANUATTI-NETO, Francisco; BIANCONI, Marcelo; GUERRERO, Dario Alexandre; YOSHINO, Joe Akira. Determinants of debt and economic regulation: an analysis of brazilian regulated infrastructure firms. SSRN, [S. I.], p. 1-23, 2017. Disponível em: https://papers.ssrn.com/sol3/papers.cfm?abstract_id=3018955. Acesso em: 10 abr. 2020.

ASSEMBLEIA LEGISLATIVA DO ESTADO DO RIO DE JANEIRO. Projeto de Lei $\mathbf{n} \mathbf{0} \mathbf{2 3 2 4 / 2 0 2 0}$. Autoriza o Estado a regular a fila única de UTI e CTI dos casos graves de COVID-19 no âmbito do estado do Rio de Janeiro, enquanto perdurar a pandemia do novo coronavirus. Rio de Janeiro: ALERJ, 2020. Disponível em: http://alerjln1.alerj.rj.gov.br/scpro1923.nsf/0c5bf5cde95601f903256caa0023131b/45394ffa 5722c88d03258544005c995c?OpenDocument\&Highlight=0,2324. Acesso em: 14 abr. 2020. 
BANCO CENTRAL DO BRASIL. Juros e spread bancário: informações até junho de 2016. Brasília, DF: Gerin, 2016. Disponível em:

https://www.bcb.gov.br/content/cidadaniafinanceira/Documents/publicacoes/serie_pmf/F AQ\%2001-Juros\%20e\%20Spread\%20Banc\%C3\%A1rio.pdf. Acesso em: 15 abr. 2020.

BARRÍA, Cecília. Deaths from cardiac arrests have surged in New York city: officials are likely to be underestimating how many may have died from covid-19. The Economist, Londres, 2020. Disponível em: https://www.economist.com/graphic-detail/2020/04/13/deaths-fromcardiac-arrests-have-surged-in-new-york-city. Acesso em: 14 abr. 2020.

BOITO JÚNIOR, Armando. As relações de classe na nova fase do neoliberalismo no Brasil. In: CAETANO, Gerardo et al. (org.). Sujetos sociales y nuevas formas de protesta en la historia reciente de América Latina. Buenos Aires: CLACSO, 2006. p. 271-296.

BRASIL. [Constituição (1988)]. Constituição da República Federativa do Brasil de 1988. Brasília, DF: Presidência da República, 1988. Disponível em: http://www.planalto.gov.br/ccivil_03/constituicao/constituicao.htm. Acesso em: 14 abr. 2020.

BRASIL. Governo Federal anuncia $\mathbf{R} \$ \mathbf{1 4 7 , 3}$ bi em medidas emergenciais para combate aos efeitos do coronavírus. Brasília, DF: Governo Federal, 2020g. Disponível em: https://www.gov.br/pt-br/noticias/financas-impostos-e-gestao-publica/2020/03/governofederal-anuncia-r-147-3-bi-em-medidas-emergenciais-para-combate-aos-efeitos-docoronavirus. Acesso em: 12 abr. 2020.

BRASIL. Lei no 13.979, de 06 de fevereiro de 2020. Dispõe sobre as medidas para enfrentamento da emergência de saúde pública de importância internacional decorrente do coronavírus responsável pelo surto de 2019. Brasília, DF: Presidência da República, 2020a. Disponível em: http://www.planalto.gov.br/ccivil_03/_ato2019-2022/2020/lei/L13979.htm. Acesso em: 12 abr. 2020.

BRASIL. Ministério da Economia. Medidas econômicas voltadas para a redução dos impactos da Covid-19 (Coronavírus) - linha do tempo. Brasília, DF: Ministério da Economia, 2020b. Disponível em: https://www.gov.br/economia/pt-br/centrais-deconteudo/publicacoes/boletins/covid-19/timeline. Acesso em: 13 abr. 2020.

BRASIL. Ministério da Economia. Transparência dos dados de dispensa para a covid-19. Brasília, DF: Ministério da Economia, 2020e. Disponível em: https://www.comprasgovernamentais.gov.br/index. php/transparencia/1284-transparenciados-dados-de-dispensa-no-combate-ao-covid-19. Acesso em: 14 abr. 2020.

BRASIL. Ministério da Saúde. Indicadores da saúde no Brasil. Brasília, DF: Ministério da Saúde, 2020d. Disponível em: https://www.saude.gov.br/dados-e-indicadores-da-saude. Acesso em: 13 abr.2020.

BRASIL. Planalto. Pronunciamento do presidente da República, Jair Bolsonaro (31/03/2020). Brasília, DF: Presidência da República, 2020c. Disponível em: 
https://www.gov.br/planalto/pt-br/acompanhe-o-

planalto/noticias/2020/03/pronunciamento-do-presidente-da-republica-jair-bolsonaro-3103-2020. Acesso em: 07 abr. 2020.

BRASIL. Supremo Tribunal Federal. Arguição de descumprimento de preceito fundamental no 671. Número único: 0089193-39.2020.1.00.0000. Relator: Min. Ricardo Lewandowski, 3 abril 2020f. Disponível em:

http://portal.stf.jus.br/processos/detalhe.asp?incidente=5884983. Acesso em: 14 abr. 2020.

CAIXA ECONÔMICA FEDERAL. Auxílio emergencial. [Brasília, DF], 2020a. Disponível em: <caixa.gov. br/programas-sociais/bolsa-familia/Paginas/default.aspx>. Acesso em: $11 \mathrm{abr}$. 2020.

CAIXA ECONÔMICA FEDERAL. Nossa História. [Brasília, DF], 2020b. Disponível em: www.caixa.gov.br/nossahistoria. Acesso em: 10 abr. 2020.

CÂMARA DOS DEPUTADOS. Proposta amplia Bolsa Família durante pandemia: deputada alerta que, em razão do isolamento social, muitas famílias estão gastando mais com alimentação de crianças e adolescentes. Brasília, DF: Câmara dos Deputados, 2020. Disponível em: https://www.camara.leg.br/noticias/649541-proposta-amplia-bolsa-familiadurante-pandemia/. Acesso em: 15 abr. 2020.

CENCI, Ana Righi; BEDIN, Gabriel de Lima; FISCHER, Ricardo Santi. Do liberalismo ao intervencionismo: o estado como protagonista da (des)regulação econômica. Constituição, Economia e Desenvolvimento: Revista da Academia Brasileira de Direito Constitucional, Curitiba, n. 4, p. 77-97, 2011.

CONSELHO FEDERAL DE MEDICINA. Menos de $10 \%$ dos municípios brasileiros possuem leito de UTI. Brasília, DF: CFM, 2018. Disponível em:

https://portal.cfm.org.br/index.php?option=com_content\&view=article\&id=27828:\%202018 -09-04-19-31-41\&catid=3. Acesso em: 14 abr. 2020.

CORONAVÍRUS: Maia diz que governo demorou a apresentar resposta. [S. I.: s. n.], 2020. 1 vídeo (5 min). Publicado pelo canal Band Jornalismo. Disponível em: https://www.youtube.com/watch?v=RWMEeMTDbz4. Acesso em: 11 abr. 2020.

CRODA, Julio Henrique Rosa; GARCIA, Leila Posenato. Resposta imediata da vigilância em saúde à epidemia da COVID-19. Epidemiol. Serv. Saúde, Brasília, DF, v. 29, n. 1, p. 1-3, 2020. Disponível em: https://www.scielo.br/pdf/ress/v29n1/2237-9622-ress-29-01-e2020002.pdf. Acesso em: 14 abr. 2020.

DOMINGUES, Edson Paulo; CARDOSO, Débora Freire; MAGALHÃES, Aline Souza. Nota técnica NEMEA: efeitos econômicos negativos da crise do corona vírus tendem a afetar mais a renda dos mais pobres. [Minas Gerais]: NEMEA: Cedeplar, 2020. Disponível em: https://www.cedeplar.ufmg.br/component/phocadownload/category/18noticias?download=1302: covid-e-renda-familiar. Acesso em 8 abr. 2020. 
FLAESCHEN, Hara. Coronavírus nas favelas: "é difícil falar sobre perigo quando há naturalização do risco de vida". Rio de Janeiro: ABRASCO, 2020. Disponível em: https://www.abrasco.org.br/site/noticias/saude-da-populacao/coronavirus-nas-favelas-edificil-falar-sobre-perigo-quando-ha-naturalizacao-do-risco-de-vida/46098/. Acesso em: 15 abr. 2020.

FUNDAÇÃO OSWALDO CRUZ. SUS. [S. I.], 2020. Disponível em: https://pensesus.fiocruz.br/sus. Acesso em: 5 mar. 2020.

GIAMBIAGI, Fabio; HORTA, Guilherme Tinoco de Lima. $\mathbf{O}$ teto do gasto público: mudar para preservar. Rio de Janeiro: Banco Nacional de Desenvolvimento Econômico e Social, 2019.

GOVERNO do RJ confirma a primeira morte por coronavírus: vítima é uma mulher de 63 anos que tinha diabetes e hipertensão: ela trabalhava como empregada doméstica de uma mulher que testou positivo para a doença. G1, [S. I.], 2020. Disponível em: https://g1.globo.com/rj/rio-de-janeiro/noticia/2020/03/19/rj-confirma-a-primeira-mortepor-coronavirus.ghtml. Acesso em: 14 abr. 2020.

GUIMARÃES, Ligia. Governo acerta na direção, mas atraso nas medidas contra coronavírus aumenta riscos, dizem economistas. BBC News Brasil, [S. I.], 2020. Disponível em: https://www.bbc.com/portuguese/brasil-52130314. Acesso em: 15 abr. 2020.

GUROVITZ, Helio. Coronavírus - um gráfico explica a pandemia. [S. I.], 2020. Disponível em: http://www.hemosc.org.br/noticia/530.html. Acesso em: 13 abr. 2020.

HERDY, Thiago. 'Isolamento é coisa de comunista': os zaps bolsonaristas durante a pandemia: o dia a dia de grupos de whatsapp a favor do presidente nas discussões sobre a Covid-19. Época, [S. I.], 2020. Disponível em: https://epoca.globo.com/brasil/isolamentocoisa-de-comunista-os-zaps-bolsonaristas-durante-pandemia-1-24347242. Acesso em: 13 abr. 2020.

HOLLAND, Márcio. Seminário: a nova lei das estatais: uma proposta de metodologia para avaliação de conformidade legal. Brasíia, DF: TCU, 2017. Disponível em: https://fgvprojetos.fgv.br/sites/fgvprojetos.fgv.br/files/arquivos/marcio_holland.pdf. Acesso em: 13 abr. 2020.

KAFRUNI, Simone. Brasil descobre remédio com 94\% de eficácia no combate à Covid-19. Estado de Minas, Belo Horizonte, MG, 2020. Disponível em: https://www.em. com.br/app/noticia/nacional/2020/04/15/interna_nacional,1138785/brasil-descobreremedio-com-94-de-eficacia-no-combate-a-covid-19.shtml. Acesso em: 15 mar. 2020.

LIU, Jia; CAO, Ruiyuan; XU, Mingyue; WANG, Xi, ZHANG, Huanyu; HU, Hengrui; LI, Yufeng; HU, Zhihong; ZHONG, Wu; WANG, Manli. Hydroxychloroquine, a less toxic derivative of chloroquine, is effective in inhibiting SARS-CoV-2 infection in vitro. Cell Discovery, [S. I.], v. 6, n. 1, p. 1-4, 2020. Disponível em: https://www.nature.com/articles/s41421-020-0156-0. Acesso em: 8 abr. 2020. 
MAGNOLI, Demétrio. Nós esclarecidos, precisamos pensar fora da bolha da alta classe média. Folha de São Paulo, São Paulo, SP, 2020. Disponível em: https://www1.folha.uol. com.br/colunas/demetriomagnoli/2020/03/nos-esclarecidos-precisamos-pensar-fora-dabolha-da-alta-classe-media.shtml. Acesso em: 8 abr. 2020.

MARTINS, Pedro. População negra e Covid-19: desigualdades sociais e raciais ainda mais expostas. Rio de Janeiro: ABRASCO, 2020. Disponível em:

https://www.abrasco.org.br/site/noticias/sistemas-de-saude/populacao-negra-e-covid-19desigualdades-sociais-e-raciais-ainda-mais-expostas/46338/. Acesso em: 15 abr. 2020.

NÚMERO de casos de coronavírus no Brasil é 15 vezes maior que dados oficiais, apontam pesquisadores: grupo de estudiosos temem que subnotificação resulte em "catástrofe" no país. Estado de Minas, Belo Horizonte, MG, 2020. Disponível em:

https://www.em.com.br/app/noticia/nacional/2020/04/16/interna_nacional, 1139250/ numero-de-casos-de-coronavirus-no-brasil-e-15-vezes-maior. shtml. Acesso em: 16 abr. 2020.

ORGANIZAÇÃO DAS NAÇÕES UNIDAS. FMI prevê para este ano maior recessão global desde 1929. [S. I.], 2020. Disponível em: https://nacoesunidas.org/fmi-preve-para-este-ano-maiorrecessao-global-desde-1929/. Acesso em: 15 abr. 2020.

ORGANIZAÇÃO PAN-AMERICANA DE SAÚDE (Brasil). OMS afirma que COVID-19 é agora caracterizada como pandemia. Genebra: OMS, 2020. Disponível em: https://www.paho.org/bra/index.php?option=com_content\&view=article\&id=6120:omsafirma-que-covid-19-e-agora-caracterizada-como-pandemia\&ltemid=812. Acesso em: 10 abr. 2020.

PAULO Guedes, Ministro da Economia. [S. I.: s. n.], 2020. 1 vídeo (124 min). Publicado pelo canal XP Investimentos. Disponível em: https://www.youtube.com/watch?v=voghPHGSPms. Acesso em: 15 abr. 2020.

POCHMANN, Marcio. Estado e capitalismo no Brasil: a inflexão atual no padrão das políticas públicas do ciclo político da nova república. Educação \& Sociedade, [S. I.], v. 38, n. 139, p. 309-330, 2017.

PORTO, Maria Célia da Silva. Estado e neoliberalismo no Brasil contemporâneo: implicações para as políticas sociais. In: JORNADA INTERNACIONAL DE POLÍTICAS PÚBLICAS, 4., 2009, São Luís, MA. Anais [...]. São Luís, MA: UFMA, 2009. Disponível em: http://www.joinpp.ufma.br/jornadas/joinppIV/eixos/1_Mundializacao/estado-eneoliberalismo-no-brasil-contemporaneo.pdf. Acesso em: 10 abr. 2020.

QUE países e territórios ainda não têm casos confirmados de coronavírus?. BBC News Brasil, [S. I.], 2020. Disponível em: https://www.bbc.com/portuguese/internacional-52136748. Acesso em: 17 abr. 2020.

ROBERTS, Siobhan. Flattening the coronavirus curve: one chart explains why slowing the spread of the infection is nearly as important as stopping it. The New York Times, [S. I.], 
2020. Disponível em: https://www.nytimes.com/article/flatten-curve-coronavirus.html. Acesso em: 13 abr. 2020.

SALES, Handerson Leonidas; CARDOSO, Antônio Dimas. Neoliberalismo no Brasil: agravamento da ausência de um capitalismo autônomo. Revista Serviço Social em Perspectiva, [S. I.], v. 4, n. (Especial), p. 304-317, 2020.

SZALAY, Eva. Trump's currency war rhetoric persists as Powell prepares to act. Financial Times, Londres, 2019. Disponível em: https://www.ft.com/content/44be1484-9f1b-11e9b8ce-8b459ed04726. Acesso em: 10 abr. 2020.

SILVA, Haína Coelho Pereira da. Governança do executivo brasileiro: efeitos da relação entre política e burocracia, ou como o presidente dorme tranquilo à noite. 2018. Dissertação (Mestrado em Ciência Política) - Faculdade de Filosofia e Ciências Humanas, Universidade Federal de Minas Gerais, Minas Gerais, 2018.

SMITH, Adam. A riqueza das nações. 4. ed. São Paulo: WMF Martins Fontes, 2016.

SUPERIOR TRIBUNAL FEDERAL. PSOL pede que STF autorize o SUS a utilizar leitos de UTIs de hospitais privados. Brasília, DF: STF, 2020. Disponível em: http://www.stf.jus.br/portal/cms/verNoticiaDetalhe.asp?idConteudo=440552. Acesso em: 09 abr. 2020.

TEIXEIRA, Carmen Fontes. Por uma análise política dos impasses da regionalização do SUS. Cad. Saúde Pública, Rio de Janeiro, v. 35, supl. 2, 2019. Disponível em: https://www.scielo.br/pdf/csp/v35s2/1678-4464-csp-35-s2-e00077019.pdf. Acesso em: 14 abr. 2020.

UNIVERSIDADE DE SÃO PAULO. Flexibilização do isolamento social pode levar à explosão de casos de covid-19: Max Igor Banks reitera que isolamento social e testes em massa são, neste momento, as estratégias mais eficazes e seguras para conter a doença causada pelo novo coronavírus. Jornal da USP, São Paulo, SP, 2020. Disponível em:

https://jornal.usp.br/atualidades/flexibilizacao-do-isolamento-social-pode-levar-a-explosaode-casos-de-covid-19/. Acesso em: 11 abr. 2020.

VECINA NETO, Gonzalo. Gestão em saúde. 2. ed. Rio de Janeiro: Guanabara Koogan, 2016.

VENTURA, Deisy de Freitas Lima; AITH, Fernando Mussa Abujamra; RACHED, Danielle Hanna. A emergência do novo coronavírus e a "lei de quarentena" no Brasil. Revista Direito e Práxis, [S. I.], p. 1-38, 2020. Disponível em: https://www.e-

publicacoes.uerj.br/index.php/revistaceaju/article/view/49180. Acesso em: 10 abr. 2020.

VIACAVA, Francisco et al. SUS: oferta, acesso e utilização de serviços de saúde nos últimos 30 anos. Ciênc. saúde coletiva, Rio de Janeiro, v. 23, n. 6, p. 1751-1762, 2018. Disponível em: http://scielo.br/pdf/csc/v23n6/1413-8123-csc-23-06-1751.pdf. Acesso em: 15 abr. 2020. 
WEISSHEIMER, Marco Aurélio. Bolsa família: avanços, limites e possibilidades do programa que está transformando a vida de milhões de famílias no Brasil. São Paulo: Fundação Perseu Abramo, 2006. Disponível em: https://fpabramo.org.br/publicacoes/wpcontent/uploads/sites/5/2017/05/Bolsa_Familia.pdf. Acesso em: 14 abr. 2020.

WILLIAMS, Sophie. Coronavírus: como a quarentena foi usada para combater doenças ao longo da história. BBC News Brasil, [S. I.], 2020. Disponível em: https://www.bbc.com/portuguese/internacional-51351780. Acesso em: 17 abr. 2020.

WORLD HEALTH ORGANIZATION. Coronavirus disease 2019 (COVID-19): situation report 85. [Genebra]: WHO, 2020. Disponível em: https://www.who.int/docs/defaultsource/coronaviruse/situation-reports/20200415-sitrep-86-covid19.pdf?sfvrsn=c615ea20_4. Acesso em: 15 abr. 2020.

Recebido em 24/04/2020.

Aceito em 11/05/2020. 